\title{
How to reach and engage social minorities - a look back on a successful involvement of pupils from all social classes
}

\author{
Anna-Lena Mädge ${ }^{a}, *$ and Isabella Pollak ${ }^{a}$, Beate Schrank ${ }^{a, b}$ \\ a Research group D.O.T., “Die offene Tür”- Ludwig Boltzmann Gesellschaft GmbH, Vienna, \\ at Karl Landsteiner Privatuniversity, Dr. Karl Dorrek Str.30, 3500 Krems an der Donau, Austria \\ b Department of Psychiatry, University Clinic Tulln, \\ Alter Ziegelweg 10, 3430 Tulln an der Donau, Austria \\ E-mail: anna.maedge@dot.lbg.ac.at, isabella.pollak@kl.ac.at, \\ beate.schrank@kl.ac.at
}

In order to develop an intervention for students, the D.O.T. project aimed at engaging children of all social backgrounds in its research, which can be challenging. D.O.T. overcame these challenges by conducting an innovative research workshop in the school setting, thus allowing all students to participate and voice their opinions. Focusing on communicating the aims and benefits of this research was crucial in the recruitment process. Researchers were available to answer all questions parents or teachers might have to increase their trust. Through personalised information efforts, a school response rate of 58\% was achieved. The final sample included students of a variety of social backgrounds, including children with migration backgrounds, children from very rural areas or social hotspots, special needs students, and high-achieving students. Innovative research activities allowed children to choose different ways to express their thoughts, ensuing all voices are heard. Researchers had to be flexible to ensure workshop appointments fit schools' schedules and flexibly adapt workshops to children's needs. Through these efforts, D.O.T. managed collect a considerable amount of data, representing ideas and opinions of children with different social backgrounds. 


\section{Introduction}

The aim of the D.O.T. project - the open door - which was generated out of a citizen science campaign, is to develop a primary intervention programme to strengthen peer connectedness [1], at the transition from primary to secondary school. Positive social relationships are important protective factors for mental well-being [2] but are frequently compromised in times of transition [3]. In line with D.O.T.'s citizen science approach, the primary aim of this project was to identify and define the research topic from the perspective of the target group of children aged 8-12 years $[4,5]$. In order to develop appropriate interventions, it is important to fully understand the experiences and needs of students from all social classes and actively involve them in all research steps [6]. Thus, innovate research methods and active recruitment procedures were employed to reach students from various backgrounds.

\subsection{Methods}

In order to ensure that every child is able to voice their opinion, research methods need to be centred around children's abilities and be subject to their own choice [6]. In order to allow all children to actively engage in research activities and secure that they are benefitting from participation [7], an innovative participatory workshop was developed in cooperation with theatre pedagogues, playwrights, rhythm-students and older students. This workshop was tested in two classrooms and adapted based on students' feedback [8]. Schools were recruited through a contact list provided by school authorities, open recruiting and personal contacts. After forwarding general information about D.O.T. via e-mail, schools were contacted individually by phone in order to discuss the details of this research. Communication about this research focused on how students' social learning would benefit from these workshops through discussing experiences around school transition and friendships and strategies to cope with difficult situations [9]. Schools were provided with detailed information letters, informing parents about the aims and procedures of the workshop and asking them to provide their written consent. Two D.O.T. employees were available around the clock for teachers' or parents' questions. In order to make participation as easy as possible, workshop appointments were tailored to suit school's schedules.

\subsection{Results}

A workshop with six different data collection activities was developed, including open discussions, small group activities, individual brainstorming activities with sticky notes and individual letters. All activities were well-received and supported participants' brainstorming process, creating about 1653 individual records of data from one brainstorming activity. Through individualized, sensitive, target group-oriented communication, this project reached more schools than planned. 50 schools were contacted and 29 schools with a total of 54 classes participated in the workshops, resulting in a response rate of 58\%. Around $72 \%$ were secondary schools and $28 \%$ were primary schools. The share of school types for secondary schools in this sample (public schools/NMS $=71 \%$, grammar schools/Gym=19\%, special education schools=18\%) was almost representative of the distribution of school types within Lower Austria (NMS $=77 \%$, Gym=13\%, and special education=12\%). Through targeted recruitment efforts, specific schools with special social profiles were be recruited, including four integration classrooms with high percentages of students with migration background, four classrooms self-defined as social hotspots, and one 
classroom with integrative support classes. $10 \%$ of schools were private schools and one school was for high-achieving students specifically. The implementation of research workshops in the school setting made it possible for children from remote rural areas (48\% of schools), and from integration and special needs schools (18\% of schools) to participate.

\section{Discussion}

Personalised and sensitive recruitment efforts, and a focus on the benefits of this research for participants, made it possible to engage $58 \%$ of initially contacted schools in this research, thus almost doubling typical mail response rates of about $30 \%$ and exceeding telephone recruitment of about 40\% [9]. Important factors to increase participation in this research, were extensive outreach efforts and the set-up of the workshops as they were free, easy accessible and adapted to the school context. Reaching out to children and their parents via school was ideal to engage children of all backgrounds, regardless of parents' level of education and affinity to research. Conducting workshops in the school setting during typical school hours allowed made it easy for school leaders and teachers to accept the offer. Reservations of educators and parents concerning research with their children were noticeable and dealing with them was a daily part of the work of the research group. It proved crucial that members of the research team were available by telephone and email to discuss all questions and concerns that parents might have. Additionally, this research aimed at benefiting participating children directly by facilitating reflection and social learning. By including a variety of innovative activities, children were provided with options to engage with the topics, helping them to reflect about their experiences and learning about possible strategies to overcome challenging situations. Individual preferences emerged; while many children at this age did not enjoy writing and thus preferred to share their ideas verbally, some children preferred to write individual, anonymous notes. Specifically, children with language barriers needed support when expressing ideas, emphasising the need to offer different methods when working with a diverse group of children. In order to conduct a large number of workshops in schools, researchers needed to demonstrate high levels of flexibility and effort, travelling frequently to fit schools' schedules, engaging with teachers and parents concerns and adapting activities on the spot to fit children's needs.

\subsection{Conclusion}

In order to achieve participatory involvement of social minorities, research settings should be part of their everyday lives and reservations regarding research need to be overcome through sensitive communication. Conducting innovative workshops in the school setting helped D.O.T. boost participation rates and engage children of all social backgrounds in research activities, which were equally informative for the design of future interventions and supportive of children's social learning.

\section{Acknowledgements}

Thanks to the Bildungsdirektion in Lower Austria for their support and to participating schools, teachers and students, who made our work possible and meaningful. 


\section{References}

[1] Schrank, B. and D.O.T. Team der Forschungsgruppe (2018), D.O.T. - Die offene Tür. psychopraxis. neuropraxis. 21(1): p. 45-49.

[2] Fuller, A., McGraw, K., \& Goodyear, M. (1999). Bungy-jumping through life: What young people say promotes well-being and resilience. Australian Journal of Guidance and Counselling, 9(1), 159168.

[3] Eder, F. (2007). Das Befinden von Kindern und Jugendlichen in der österreichischen Schule. Befragung 2005.

[4] Hecker, S., et al. (2018), Citizen Science: Innovation in Open Science, Society and Policy. London: UCL Press. p. 580.

[5] Senabre, E., N. Ferran-Ferrer, and J. Perelló (2018), Participatory design of citizen science experiments. Communicate. 54: p. 29-38.

[6] Hagen, P., Collin, P., Metcalf, A., Nicholas, M., Rahilly, K., \& Swainston, N. (2012). Participatory Design of evidence-based online youth mental health promotion, intervention and treatment. In: Young and Well Cooperative Research Centre.

[7] Heigl, F, et al. (2020). Co-Creating and Implementing Quality Criteria for Citizen Science. Citizen Science: Theory and Practice, 5(1): 23, pp. 1-11. DOI: https://doi.org/10.5334/cstp.294

[8] Research Group D.O.T. (2018), "Happy-Zone" Workshop Manual. Available: https://dot.lbg.ac.at/downloads/ .

[9] Heerman, W. J., Jackson, N., Roumie, C. L., Harris, P. A., Rosenbloom, S. T., Pulley, J., ... \& Scherdin, J. (2017). Recruitment methods for survey research: findings from the mid-south clinical data research network. Contemporary Clinical Trials, 62, 50-55. 